Dissecting electrostatic contributions to folding and self-assembly using designed multicomponent peptide systems

\author{
Avanish S. Parmar ${ }^{1}$, Jose K. James ${ }^{2}$, Daniel R. Grisham ${ }^{2}$, Douglas H. Pike², Vikas Nanda² \\ ${ }^{1}$ Department of Physics, Indian Institute of Technology (Banaras Hindu University) Varanasi-221005, \\ UP, INDIA; ${ }^{2}$ Center for Advanced Biotechnology and Medicine, Department of Biochemistry and \\ Molecular Biology, Robert Wood Johnson Medical School, Rutgers University, 679 Hoes Lane West, \\ Piscataway, NJ 08854
}


(A)

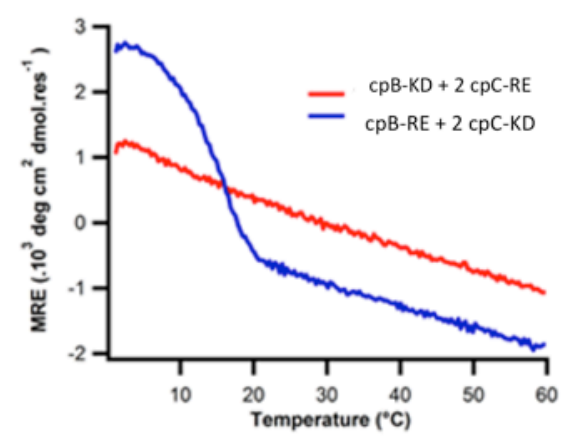

(B)

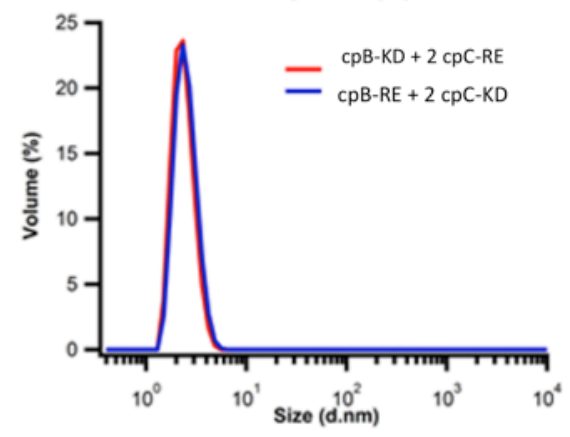

$\mathrm{cpB}-\mathrm{KD}+2 \mathrm{cpC}-\mathrm{RE}$

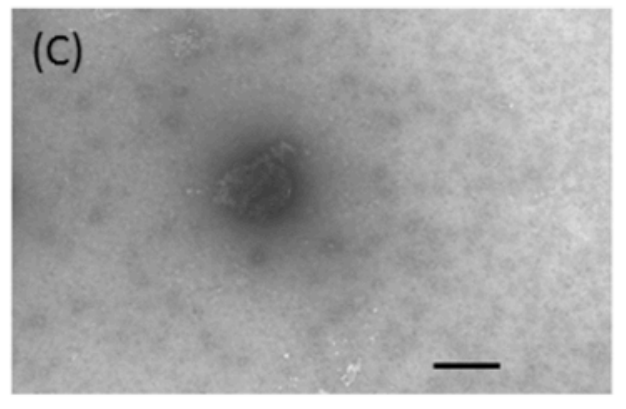

$\mathrm{CPB}-\mathrm{RE}+2 \mathrm{cpC}-\mathrm{KD}$

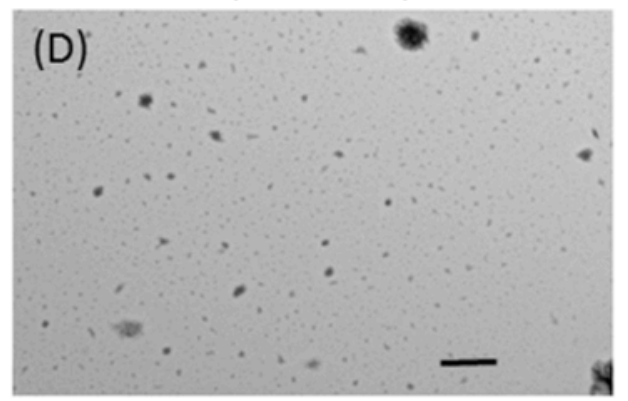

Figure S1. Effect of triple-helical structure on the aggregation of peptides: $0.2 \mathrm{mM}$ peptides were dissolved in $10 \mathrm{~mm}$ phosphate buffer, $\mathrm{pH}=7.0$ and measurements were carried out using (A) CD to perform thermal denaturation at $223 \mathrm{~nm}$ (B) DLS to measure their corresponding particle size distribution, (C) and (D) TEM for their respective morphology by TEM. Scale bar is 0.5 microns. 


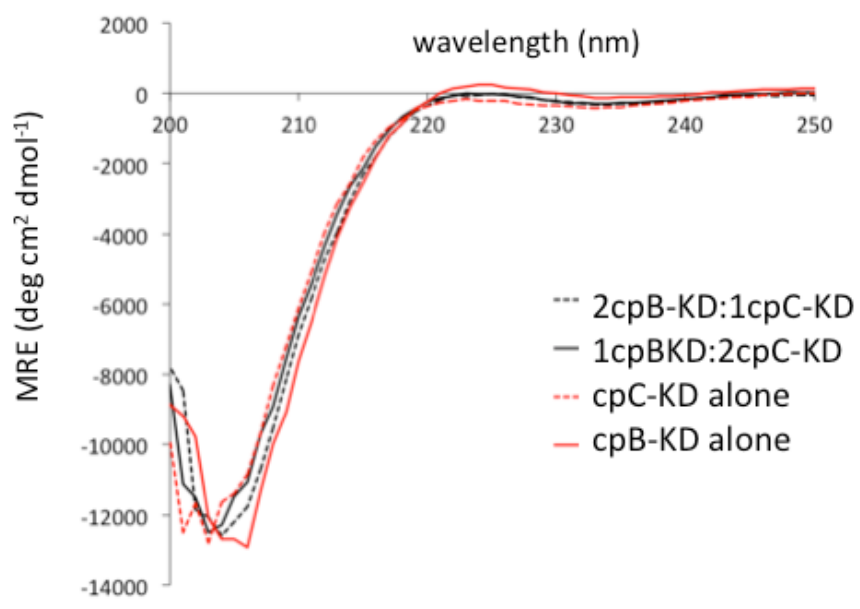

Figure S2: CD spectra of charged peptides cpB-KD and cpC-KD do not support formation of a triple-helix. (MRE = mean residue ellipticity)

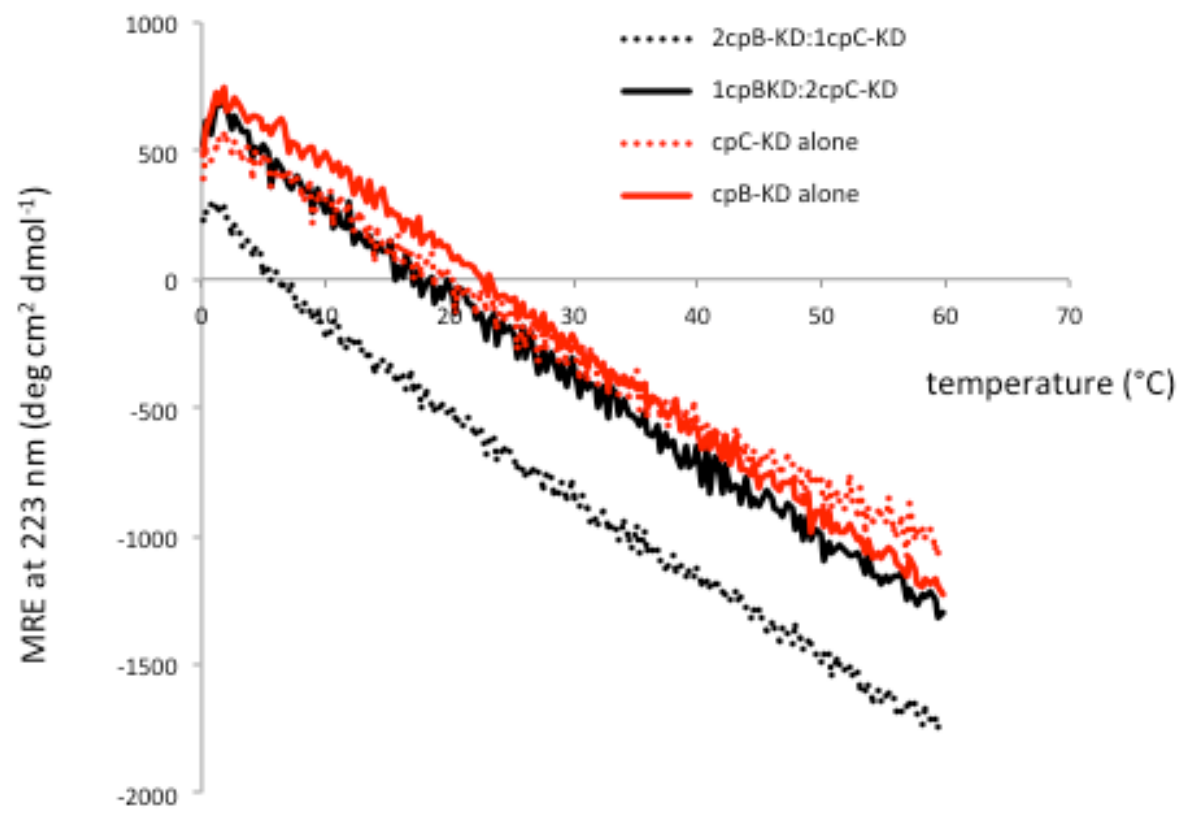

Figure S3: Thermal denaturation of $\mathrm{cpB}-\mathrm{KD}$ and $\mathrm{cpC}-\mathrm{KD}$ monitored by $\mathrm{CD}$ (mean residue ellipticity at $223 \mathrm{~nm}$ ) shows no evidence of cooperative loss of structure, indicating peptides are unfolded over this range of temperatures. 


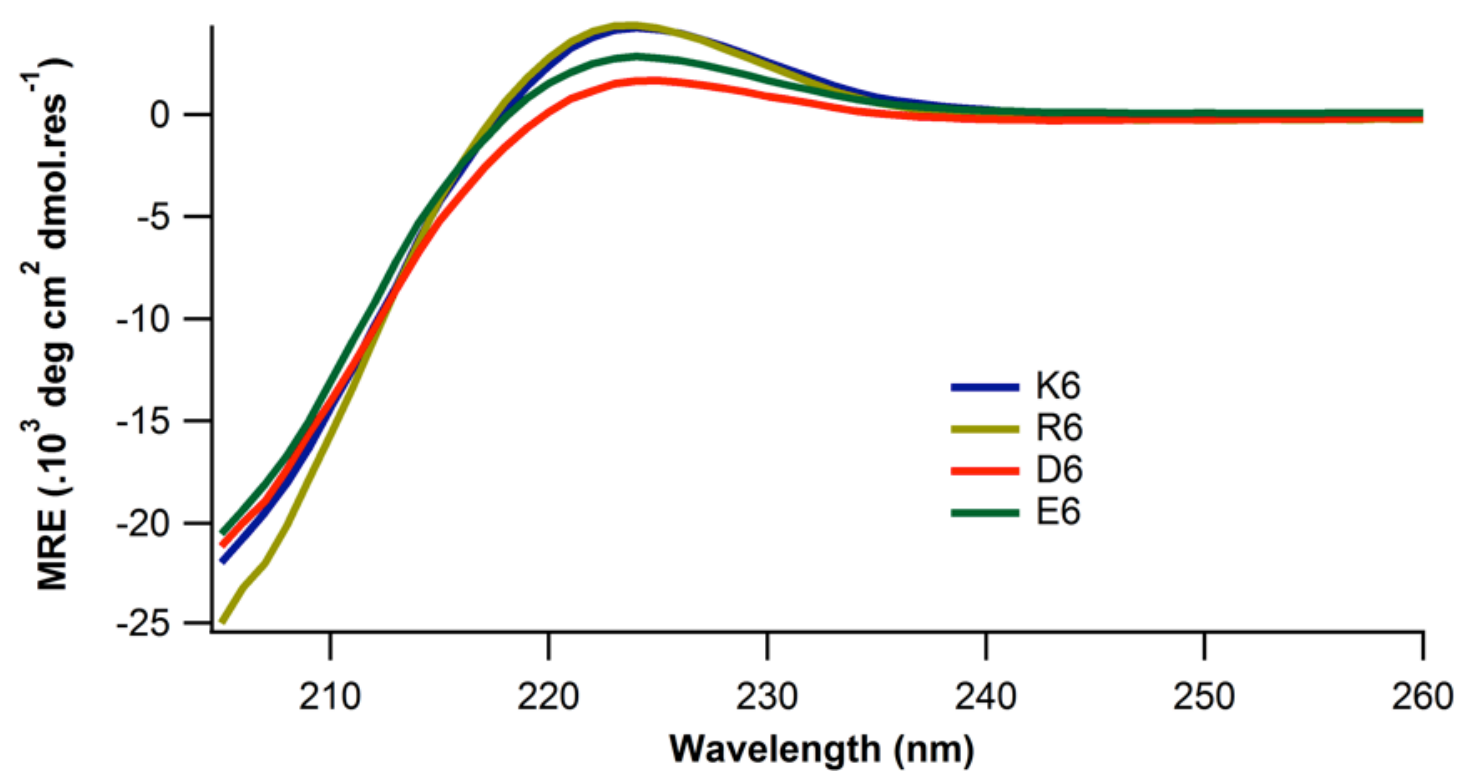

Figure S4. CD spectra of R6, K6, E6, D6 at $4{ }^{\circ} \mathrm{C}$. Loss of the positive band at $223 \mathrm{~nm}$ upon thermal denaturation (Fig 2) supports triple-helical structure for K6 and R6. Modest transitions were observed for E6 and D6 indicating a weakly stable, partially folded state. 
(A)
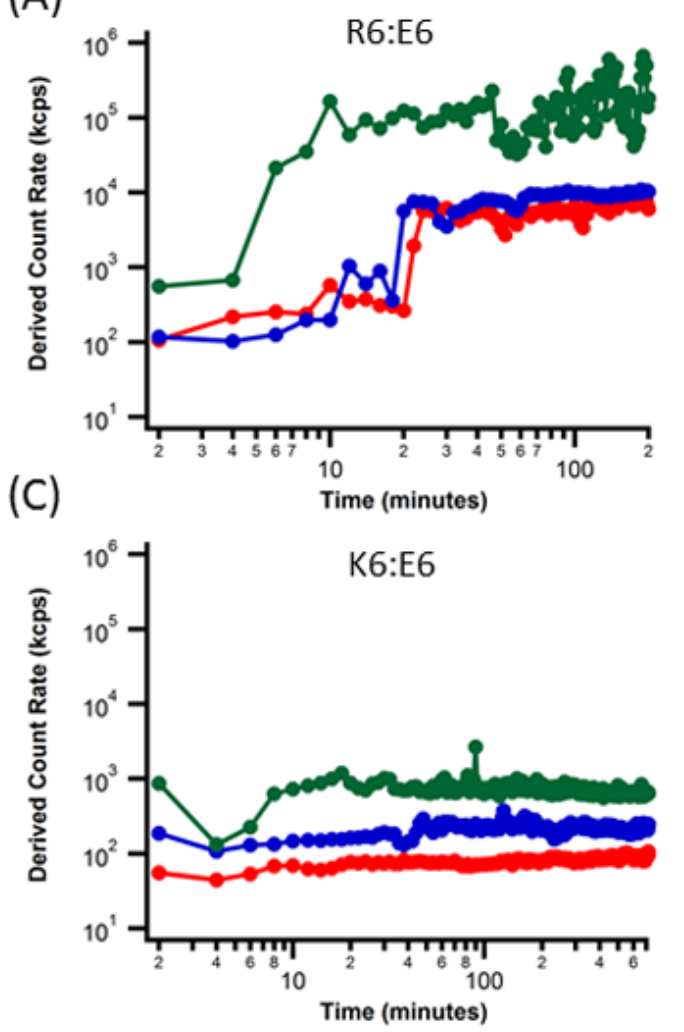

(B)
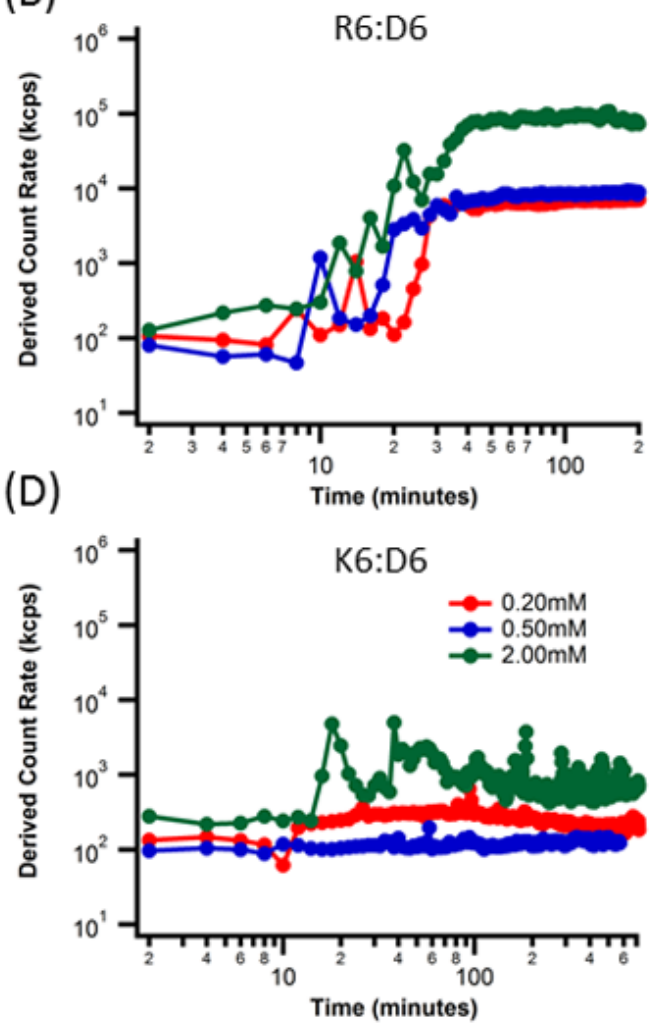

Figure S5. Effect of mixing positive and negative charged peptides on the aggregation kinetics:

Monitoring total scattering intensity by SLS at $4{ }^{\circ} \mathrm{C}$ in $10 \mathrm{mM}$ phosphate buffer, $\mathrm{pH}=7$ of a combined mixture of net positive and net negative peptides in equal ratios at various peptide concentrations (A) R6:E6, (B) R6:D6, (C) K6:E6, (D) K6:D6. 

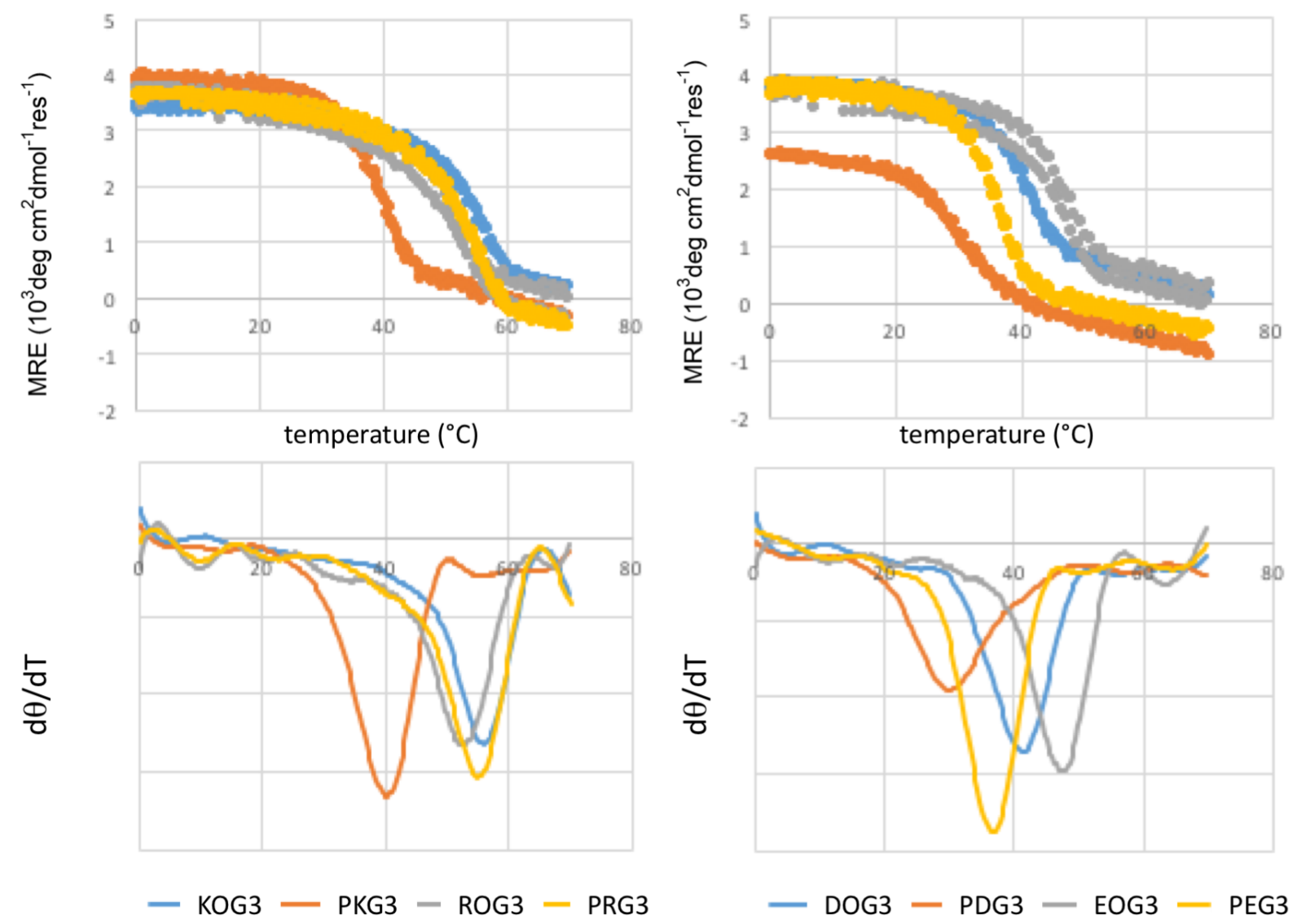

Figure S6: (top) Thermal denaturation of $(x y G)_{3}(\mathrm{POG})_{7}$ peptide homotrimers measured by circular dichroism monitored at $223 \mathrm{~nm}$. (bottom) First-derivative plots were determined by smoothing denaturation profiles using a Savitsky-Golay algorithm with nineteen points and a third-order polynomial ${ }^{1}$, and melting temperatures assigned based on extrema of the first derivative. Melting temperatures: $\mathrm{KOG} 3=56^{\circ} \mathrm{C}, \mathrm{PKG} 3=40^{\circ} \mathrm{C}, \mathrm{ROG} 3=52^{\circ} \mathrm{C}, \mathrm{PRG} 3=55^{\circ} \mathrm{C}$, DOG3 $=40^{\circ} \mathrm{C}$, PDG3 $=31^{\circ} \mathrm{C}$, EOG3 $=48^{\circ} \mathrm{C}$, PEG3 $=37^{\circ} \mathrm{C}$. 


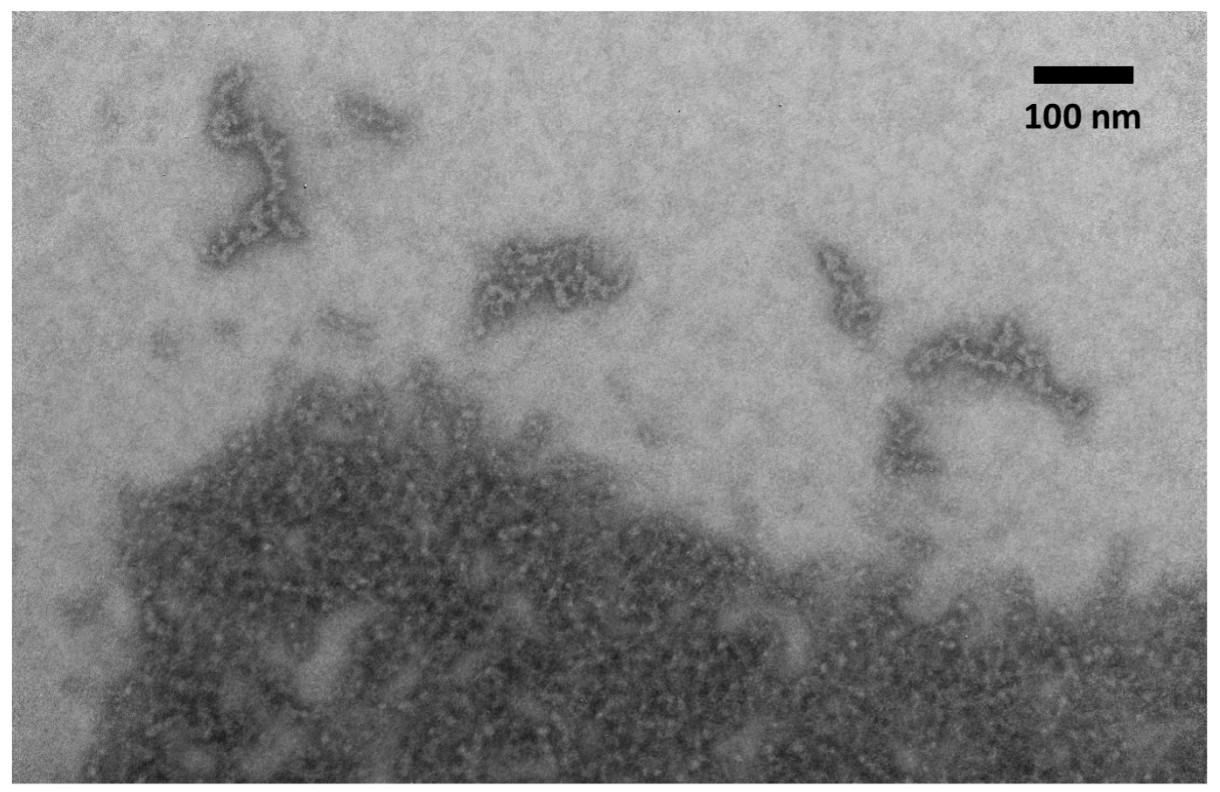

Figure S7: TEM image of PRG3 + PEG3 at $2 \mathrm{mM}$ total peptide concentration after 1 week incubated at $4^{\circ} \mathrm{C}$.
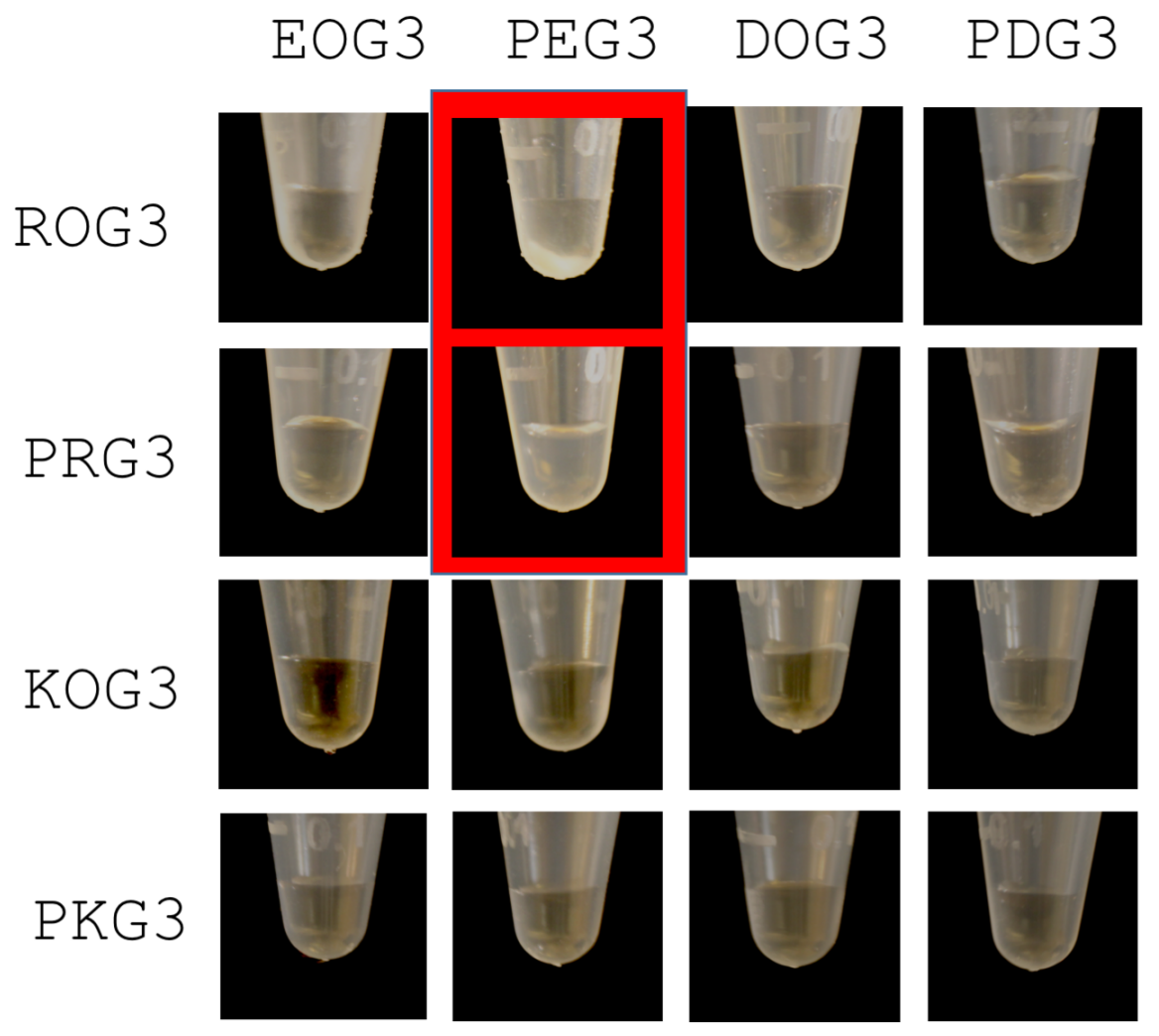

Figure S8: Mixtures of $(x y G) 3$ peptides incubated at $4^{\circ} \mathrm{C}$ for 1 week in $1.5 \mathrm{~mL}$ centrifuge tubes. Tubes were photographed using a Canon Rebel XTI camera under ambient light at fixed exposure conditions. Red outlines highlight the two aggregating mixtures. 
Figure S9: Seven structures were chosen for inspection of crystal lattice contacts mediated by arginine or lysine. Key intrahelical (red dashed lines) and interhelical (black dashed lines) interactions (less than 4.0 angstroms) are shown below. Only backbone atoms are shown for clarity unless lysine or arginine makes specific interactions with sidechain groups.

\begin{tabular}{|l|l|l|l|}
\hline $\begin{array}{c}\text { Collagen } \\
\text { Structure }\end{array}$ & Amino Acid & $\begin{array}{c}\text { Intramolecular } \\
\text { Interaction }\end{array}$ & $\begin{array}{c}\text { Intermolecular } \\
\text { Interaction }\end{array}$ \\
\hline 1BKV & Arg & Arg backbone & $\begin{array}{l}\text { Thr backbone; Thr } \\
\text { sidechain }\end{array}$ \\
\hline 1Q7D & Arg & Glu sidechain & Hyp backbone \\
\hline 3DMW & Arg & $\begin{array}{c}\text { Arg/Glu backbone; Glu/ } \\
\text { Ser sidechain }\end{array}$ & Ser/Hyp sidechain \\
\hline 4GYX & Arg & $\begin{array}{c}\text { Hyp/Met/Arg backbone; } \\
\text { Gln sidechain }\end{array}$ & Met backbone \\
\hline 1QSU & Lys & Lys backbone & \\
\hline 3PON & Lys & & Gly backbone \\
\hline 3POD & Lys & & Hyp backbone \\
\hline
\end{tabular}

ARG

$1 \mathrm{BKV}$

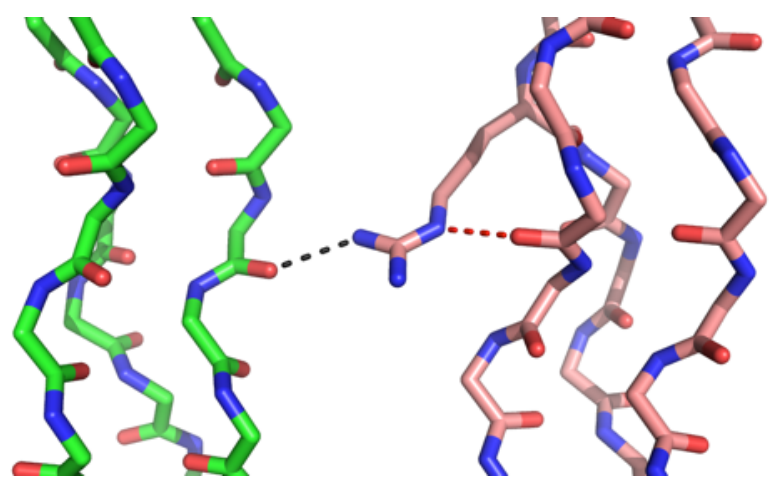

1Q7D

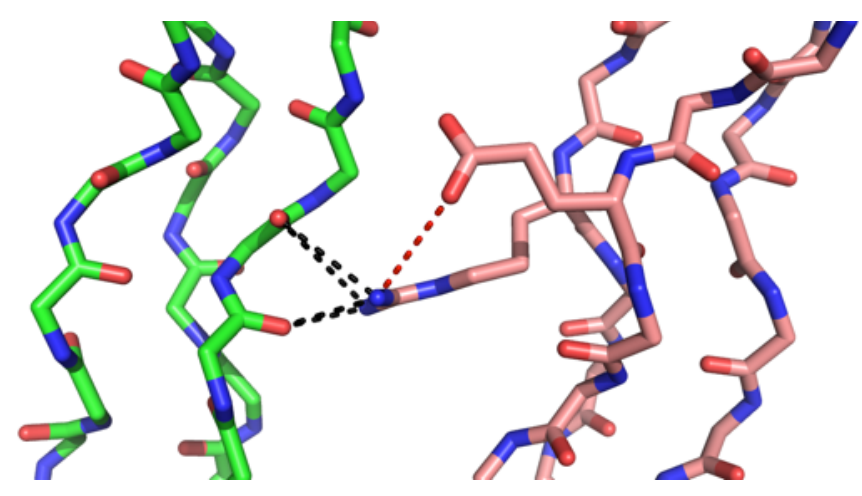



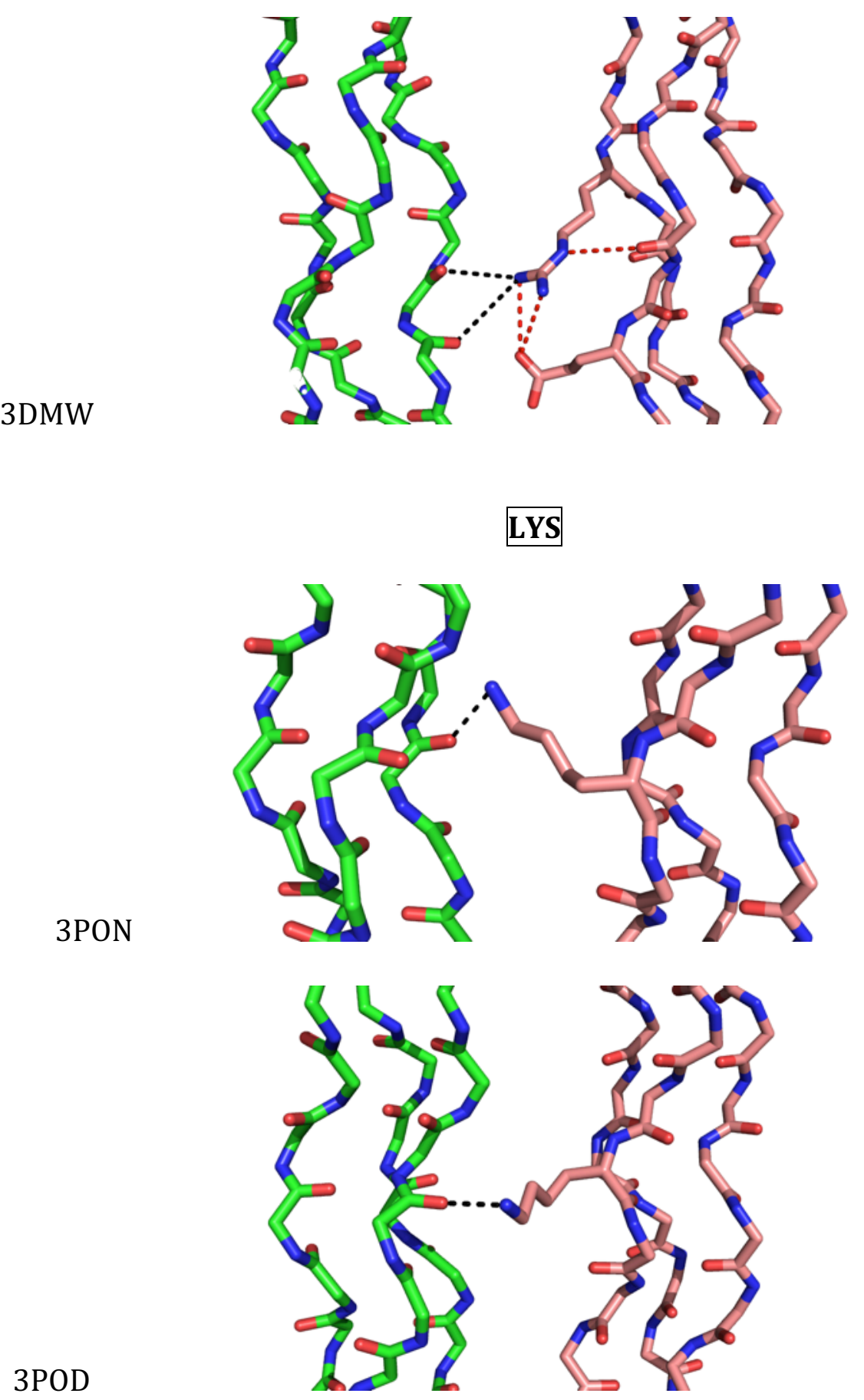

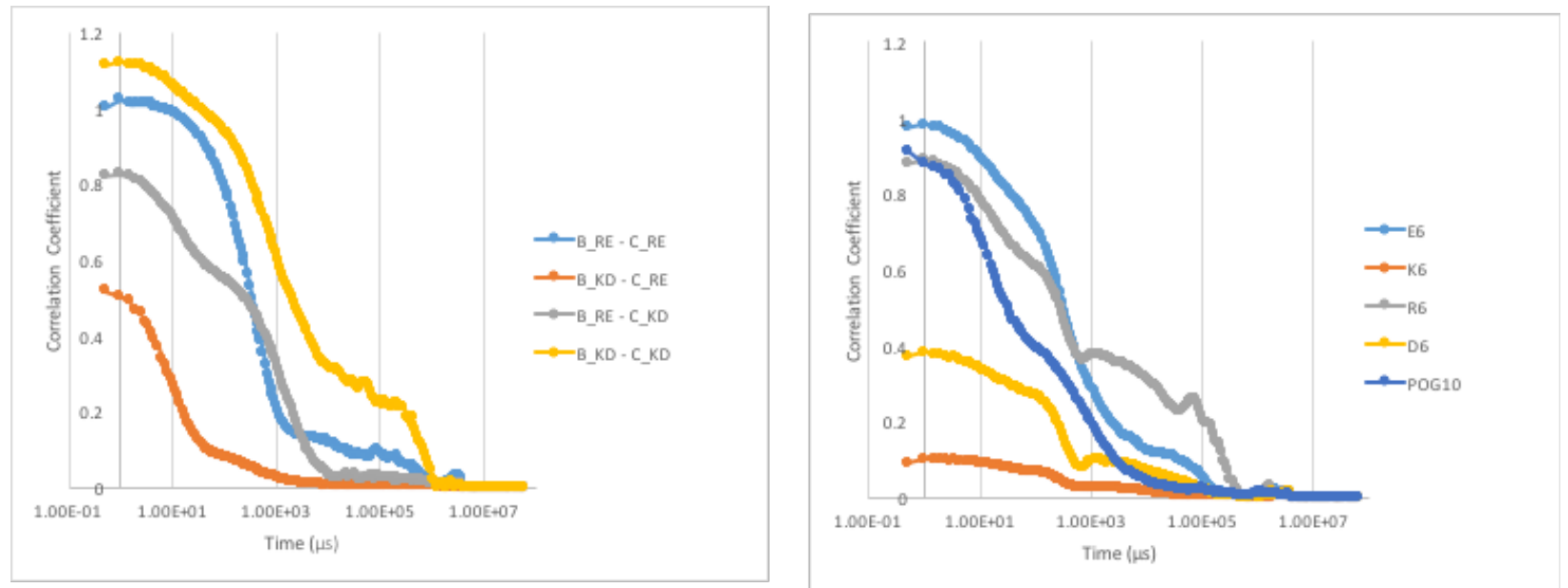

Figure S10: DLS correlation plots for $\mathrm{cpB}+\mathrm{cpC}$ mixtures (corresponding volume \% plots in Fig 1B) and for supercharged peptides (volume \% plots in Fig. 2C)

\section{Supplemental References}

(1) Savitzky, A. G., M.J.E. Anal. Chem. 1964, 36, e13. 